\title{
MANAGEMENT OF INTRACRANIAL HIGH PRESSURE ON STROKE: A NARRATIVE REVIEW
}

\author{
FRANSISCA KRISTINA ELISABET*
}

Research Assistant at Infectious Disease Control and Management (TB-HIV Working Group), Padjadjaran University, Bandung, West Java, Indonesia. Email: fransiscakristina24@gmail.com

Received: 20 January 2021, Revised and Accepted: 26 February 2021

ABSTRACT

Intracranial pressure (ICP) is a dynamic and fluctuating pressure within the cranial vault influenced by cerebrospinal fluid (CSF), brain tissue, and blood. Any increase in the volume of its contents will increase the pressure within the cranial vault. As a response to ICP, compensation begins by the movement of CSF from the ventricle to cerebral subarachnoid space and increases CSF absorption. Increased ICP is a state of neurological emergency caused by various neurological injuries. It is associated with poor outcomes, including traumatic brain injury, large acute ischemic stroke, intracerebral hemorrhage, or even death. This article aims to review the symptoms and signs of increased ICP, particularly on infarction stroke and hemorrhagic stroke condition, how the therapeutic goals of the treatment strategies and pharmacological or non-pharmacological management to mitigate the elevation of ICP on stroke.

Keywords: Cranial vault, Hemorrhage stroke, Intracranial high pressure (ICP), Management, Stroke infarction, Treatment.

(C) 2021 The Authors. Published by Innovare Academic Sciences Pvt Ltd. This is an open access article under the CC BY license (http://creativecommons.org/ licenses/by/4.0/) DOI: http://dx.doi.org/10.22159/ajpcr.2021v14i3.41146. Journal homepage: https://innovareacademics.in/journals/index.php/ajpcr

\section{INTRODUCTION}

Intracranial high pressure or intracranial hypertension $(\mathrm{IH})$ is a clinical condition associated with an elevation of the intracranial pressure (ICP) within the cranium of the skull. The cranial vault's pressure is in millimeters of mercury ( $\mathrm{mmHg}$ ) and usually is $<20 \mathrm{mmHg}$ [1-3]. Due to the skull's fixed nature, an increase in the volume of any one of the intracranial components will also cause an increase in pressure. If one of the elements within the cranium increases, a different component's volume must decrease to maintain this equilibrium and sustain a normal ICP. Many disease processes can result in IH, including traumatic brain injury, large acute ischemic stroke, and intracerebral hemorrhage (ICH).

\section{THE FUNDAMENTAL OF ICP}

The Monro-Kellie doctrine states that the intracranial space is a fixed volume inside the skull [3]. This intracranial space has three components: Brain tissue, blood, and cerebrospinal fluid (CSF). In an average adult, the brain tissue volume is $1400 \mathrm{~mL}$; the blood volume is $150 \mathrm{~mL}$; and the CSF volume is $150 \mathrm{~mL}$ [3]. Normal ICP ranges 3-15 mmHg; in the intensive care unit, ICP values $<20 \mathrm{mmHg}$ are still acceptable. The pathological status in the intracranial vault that results in increased volume may be associated with the extrinsic mass lesion, increase in blood volume, increase in CSF volume, and increase in brain tissue.

There is a reduction in the volume of other compartments as a compensatory mechanism to maintain the normal value of ICP. As compliance decreases, there is a more significant change in pressure for a given change in volume (i.e., there are dramatic changes in pressure for small incremental changes in volume) (Fig. 1). This ICP is reflected in the ICP waveform, as shown in Fig. 2 .

Changes in ICP are associated with volume changes in one or more constituents inside the cranial vault [4]. The cranial vault and spinal canal, along with the relatively inelastic dura, form a rigid vessel. Hence, any increase in brain, blood, or CSF will tend to increase ICP. Moreover, any enhancement of one component must be at the other two's expense (Monro-Kellie's doctrine, Fig. 3). The small increase in brain volume does not lead to an immediate increase of ICP, because CSF is transferred to the spinal canal and stretching the cerebral falx.
However, once the ICP has reached about $25 \mathrm{mmHg}$, a small increase in brain volume can increase ICP [5-8].

The cerebrovascular circulation is a complex network consisting of arteries and veins. The pressure difference that forces blood to enter this system is known as the cerebral perfusion pressure (CPP). We define $\mathrm{CPP}$ as mean arterial pressure (MAP) minus ICP (i.e., CPP=MAPICP). Therefore, as ICP rises, CPP will fall. Normal CPP is $60-150$ $\mathrm{mmHg}$; $\mathrm{CPP}<60 \mathrm{mmHg}$ may result in ischemic brain injury; while CPP $>150 \mathrm{mmHg}$ can lead to hyperemia and cerebral hyperperfusion injury [9]. Cerebral blood flow (CBF) is the blood flow supply to the brain. In adults, normal $\mathrm{CBF}$ is around $15 \%$ of cardiac output. We can calculate CBF values with CPP values divided by cerebrovascular resistance (CVR) values. We can simplify CPP approximately as the same inlet pressure with MAP minus the exit pressure equal to the ICP $(\mathrm{CPP}=$ MAP-ICP) $[4,7,8,10]$.

\section{PATHOPHYSIOLOGY OF INCREASED ICP ON STROKE}

The main pathophysiology's of ICP consists of cerebral edema, obstruction of CSF flow, increased cerebral blood volume, and expansion of brain mass. Cerebral edema is a complication of all types of stroke. The timing varies from the first $24 \mathrm{~h}$ to approximately $72 \mathrm{~h}$ after onset [11]. Cerebral edema can be divided into cytotoxic, vasogenic, and interstitial edema (IE) [12].

\section{Cytotoxic edema (CE)}

$\mathrm{CE}$ is an inflammation of the brain cell elements (neurons, glia, and endothelial cells) due to metabolism failure of cellular energy. It is typically accompanied by brain swelling and can result from almost any insult to the brain, including trauma, infarction, neoplasm, abscess, or conditions such as hypoxia, toxic, and metabolic perturbation [12].

Vasogenic edema (VE)

VE occurs due to increased permeability of the blood-brain barrier (BBB) against serum elements. Its development reflects damage to the endothelial cells that form the BBB.

\section{Interstitial edema (IE)}

IE occurs due to osmotic differences between plasma and brain tissue. In general, it happens in obstruction hydrocephalus that increases transependymal CSF flow. There is an increase in sodium and water 
in the periventricular substantia alba (white matter) with the displacement of CSF passing through the ventricular epithelium.

\section{INTRACRANIAL HIGH PRESSURE ON STROKE CASES}

\section{Stroke infarction}

Ischemic areas are formed due to decreased regional CBF of the brain isolated from the bloodstream. In that region, we find: (1) Low perfusion pressure, (2) decreased pressure of oxygen, and (3) CO2 and accumulated lactic acid. Autoregulation and vasomotor in that area work together to overcome ischemic conditions by providing maximum vasodilation. Collateral vasodilation occurred at the border of the ischemic areas so

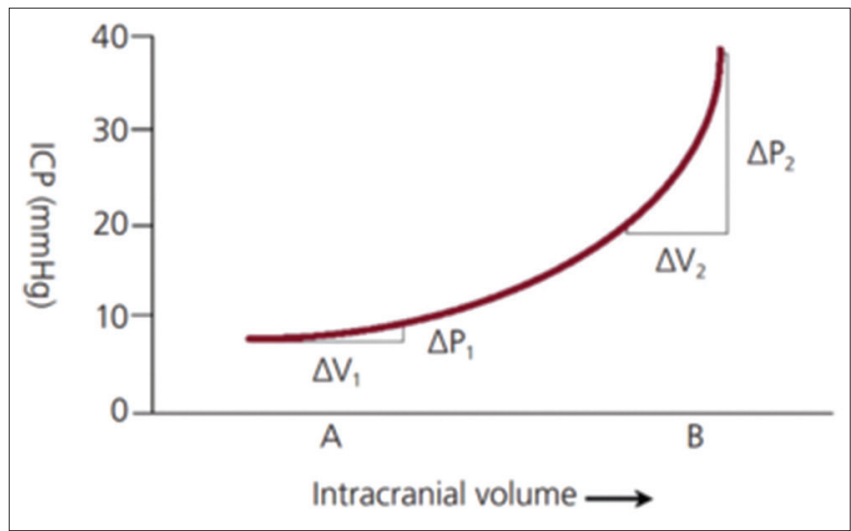

Fig. 1: Intracranial pressure-volume relationship

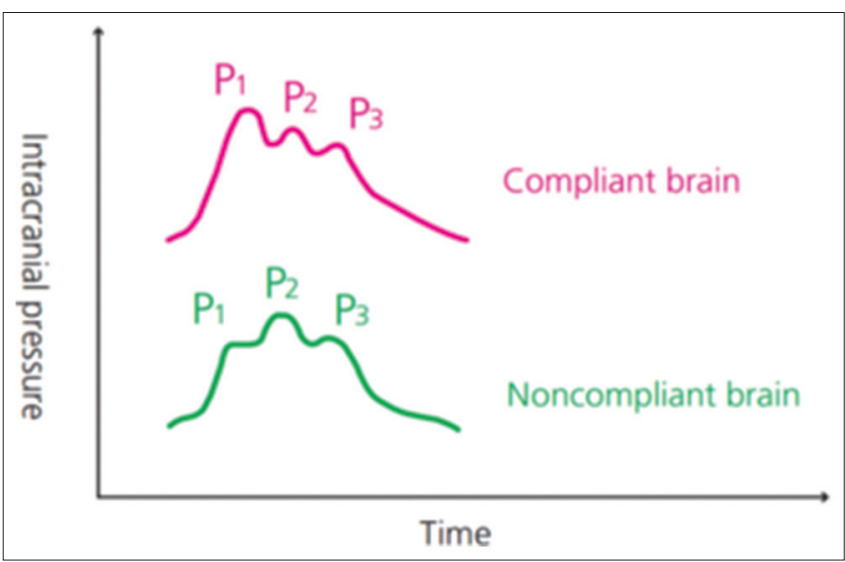

Fig. 2: Intracranial pressure waveform. Normal compliance and decreased compliance that we can save it. Central ischemic areas that cannot be resolved by autoregulation mechanisms and vasomotor management will develop irreversible degeneration processes. All blood vessels in the central part of the ischemic area lose tone and therefore in a vasoparalysis state. The picture is appropriate with the ischemic circumstances. We can repair because blood vessels' smooth muscle cells can survive long enough in an anoxic environment. However, the brain cells of the ischemic region do not stay long. Swelling of nerve fibers and myelin sheath (cerebral edema) is an early degenerative reaction followed by diapedesis of erythrocytes and leukocytes. Eventually, the nerve cells are destroyed, resulting in an infarct image $[13,14]$.

In areas of edema, cerebral autoregulation is impaired. Vasodilators dilate the lumen of healthy cerebral blood vessels, but the swollen area's veins cannot do the same. Blood will flow through the dilated healthy cerebral arteries. Thereby, only healthy brain tissue will receive it. This phenomenon is known as cerebral steal syndrome. On the contrary, vasoconstriction due to hypocapnia or specific anesthetic agents, such as thiopentone, will reduce blood flow to healthy brain tissue, resulting in a redistribution of blood ischemic areas. This phenomenon is called inverse steal syndrome [15].

Cerebral edema increases the resistance, thereby decreasing blood flow to the brain [14]. Efforts to improve regional cerebral ischemia will be fruitless if the cerebral edema region is not eradicated quickly. A reduction in total CBF will reduce regional CBF. The first action in the acute stage of ischemic stroke aims to maintain optimal perfusion pressure. For high systemic blood pressure to increase total $\mathrm{CBF}$, intracranial resistance due to cerebral edema must be overcome [14]. CE occurs in the $1^{\text {st }} \mathrm{h}$ after stroke ischemia onset, and we can detect a decrease in the apparent diffusion coefficient (ADC) of water. We also observe a reduction of ADC in acute hemorrhage stroke, but it is different from ischemic stroke. ADC continues to decline for up to 100 days after onset [15].

Normal cell volume depends on the electrolyte balance, also extracellular and intracellular fluid exchanges. This balance depends on the low permeability of the membrane to sodium, the energydependent membrane pump, and the energy supply in adenosine triphosphate (ATP). When the ischemic process becomes an infarction, the homeostatic function that controls cell volume and the BBB permeability is impaired because the ATP-dependent $\mathrm{Na}+\mathrm{K}+$ ATPase pump cannot function without ATP. This infarction results in the entry of $\mathrm{Na}+$ into the cells, followed by $\mathrm{Cl}$ - and water, resulting in edema. This cascade impairs control mechanisms of the cell volume and develops CE [14]. As with the CE that precedes it, VE also grows due to energy failure, glutamate release, and increased intracellular calcium concentration. Free radicals also play a role in the formation of ischemic VE [14]. This edema process will increase ICP, which occurs in large stroke infarction.

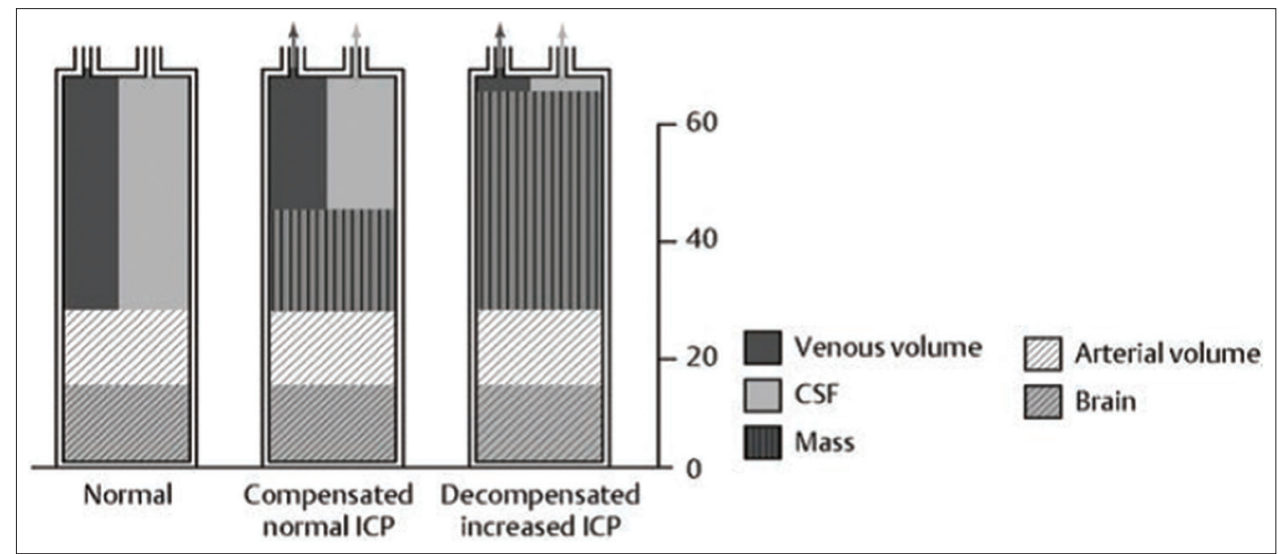

Fig. 3: Compensated intracranial pressure (ICP). The intracranial space's normal condition includes the parenchyma brain, arterial volume, venous blood, and cerebrospinal fluid (CSF). If there is a mass, there are blood suction and CSF to reach the compensated normal ICP. 


\section{Hemorrhage stroke}

Perihematomal edema appears in the first few days after the onset of ICH. Experimental studies suggest that the multifactorial perihematomic edema mechanism can form CE and/or VE [16]. In an ICH, CE is predominantly present. This edema is related to the size of the hematoma, not to the severity of the hypoperfusion. Perihematomal CE may be associated with the accumulation of cytotoxic factors such as thrombin or iron

The formation of edema in ICH occurs through the three stages; in the first few hours after ICH, there is a clot formation. Intact red blood cells in the area of the hematoma do not cause edema. After the coagulation cascade becomes active over the next 24-48 h, thrombin becomes active and impairs the BBBs integrity, allowing intravascular fluid to enter the extracellular space. The third phase occurs when the hematoma red blood cells begin to lysis. Hemoglobin and its degradation products are stored in the brain parenchyma, causing a potent inflammatory reaction and edema formation. Blood in the subarachnoid causes vasospasm that increases CVR, decreases CBF, even though CPP is normal [17].

The ICP will continue to increase, thereby endangering the CPP. The CPP will be zero if the ICP is equal to the mean artery. The brain becomes ischemic with irreversible neurological damage. Brain death occurs when the ICP equals arterial pressure $[5,10]$.

\section{MANIFESTATIONS OF ICP AND ITS MANAGEMENT}

Early signs of ICP are headache, vomiting, seizure, and decreased consciousness. Several complications include breathing and airway problems, reduced life span, difficulty communicating, permanent loss of brain functions and movement, or sensation [11]. Moreover, patients may develop altered midline shifts that show dilated or unreactive pupils, asymmetric pupils, extensor posturing, progressive neurologic deterioration, and decrease in the Glasgow Coma Scale score [13]. We can observe other manifestations such as papilledema, bradycardia, progressive increase in blood pressure, and endocrine disorders. In children, the head circumference may be enlarged by widening the cranial sutures. The most common neurological disorders are paralysis of the VI and III nerves and positive Babinski's sign on both sides [4-6,10,18,19].

Prompt recognition and aggressive management of complication may prevent permanent neurological dysfunction or death by the interdisciplinary [20]. Management of increased ICP has to be established into pharmacotherapy and non-pharmacotherapy approaches. Pharmacotherapy intervention comprises hyperosmolar therapy, euglycemia, hyperventilation, optimal oxygenation, controlling cerebral metabolism (sedation), barbiturate coma, anticonvulsant prophylaxis, maintenance of normothermia, and coagulation therapy. Furthermore, non-pharmacotherapy consists of positioning, initial trauma assessment (airway, breathing, and circulation), suctioning, control fluid and electrolytes, and nutrition [21].

Clinician and medical personnel should have sufficient knowledge and skills to support ventilation and deal with oxygenation problems (airway obstruction, increased PaC02, and hypoxemia), positioning (head on the bed 15-30 degree), reduce increased metabolic rate, reduce stressors (pain, disturbing conversation, noise, and bright lights), and others such as avoiding Valsalva maneuver, coughing, and vomiting. Furthermore, they have to establish a baseline neurologic assessment, patients' electrolytes, oxygen saturation, and carbon dioxide levels [22] and monitor cerebral tissue perfusion, fluid volume, breathing pattern, body temperature, risk infection, injury, and altered nutrition $[23,24]$. Initial and promptly assessment and early aggressive resuscitation of critically ill patients may prolong life.

\section{CONCLUSION}

The progressive increase in intracranial compartment volume can cause an increase in intracranial pressure. Increased ICP is an emergency case where we can avoid irreversible brain injury with appropriate intervention on time. On stroke cases, the progressive increase of ICP very important and essential to determine the brain function. Increased ICP can also decrease the cerebral blood flow or brain herniation resulting in compression and cerebral ischemia. Common symptoms of ICP are headache, projectile vomiting, seizures, and changes in mental status, while the most reliable physical signs are papilledema. Handling ICP aims to reduce pressure intracranial, increase cerebral blood flow, and restore brain herniation. Management of increased intracranial pressure on stroke consists of pharmacotherapy and nonpharmacotherapy administration. The clinician and medical personnel should have sufficient knowledge and skills regarding ICP management on stroke to decrease its morbidity and mortality.

\section{REFERENCES}

1. Marmarou A, Anderson RL, Ward JD, Choi SC, Young HF, Eisenberg HM, et al. Impact of ICP instability and hypotension on outcome in patients with severe head trauma. J Neurosurg 1991;75:S1-66.

2. Cremer OL, van Dijk GW, van Wensen E, Brekelmans GJ, Moons KG, Leenen LP, et al. Effect of intracranial pressure monitoring and targeted intensive care on functional outcome after severe head injury. Crit Care Med 2005;33:2207-13.

3. Mayer SA, Chong JY. Critical care management of increased intracranial pressure. J Intensive Care Med 2002;17:55-67.

4. Snell RS. Clinical Neuroanatomy for Medical Student. $3^{\text {rd }}$ ed. Boston: Little Brown and Company; 1982. p. 1-9.

5. Lee KR, Hooff JT. Intracranial pressure. In: Neurological Surgery. $4^{\text {th }}$ ed. Philadelphia, PA: WB Saunders Company; 1996. p. 491-514.

6. Lindsay KW, Bone I, Callander R. Neurology and Neurosurgery Illustrated. $3^{\text {rd }}$ ed. New York: Churchill Livingstone; 1997. p. 72-80.

7. Victor M, Ropper AH. Adam and Victor's Principles of Neurology. $7^{\text {th }}$ ed. New York: McGraw-Hill Medical Publisihing Division; 2001. p. 655-74.

8. Walter FJ. Intracranial pressure and cerebral blood flow. Physiology 1998;8:1-4.

9. Latorre JG, Greer DM. Management of acute intracranial hypertension: A review. Neurologist 2009;15:193-207.

10. Ward JD, Mopulton RJ, Muizelaar JP, Marmaraou A. Cerebral homeostasis and protection. In: Neurological Critical Care. $7^{\text {th }}$ ed., Vol. 1. Baltimore: Williams and Wilkins; 1991. p. 187-206.

11. Rockoff MA, Ropper AH. Physiology and clinical aspect of raised intracranial pressure. In: Neurological and Neurosurgical Intensive Care. $3^{\text {rd }}$ ed. New York: Raven Press; 1993. p. 11-66.

12. Juul N, Duch B, Rasmussen M. Clinical management of patients with head injury. Curr Anaesth Crit Care 2009;20:132-7.

13. Rosand J, Schwamm LH. Management of brain edema complicating stroke. J Intensive Care Med 2001;16:128-41.

14. Raslan A, Bhardwaj A. Medical management of cerebral edema. Neurosurg Focus 2007;22:E12.

15. Mishra LD. Cerebral blood flow and anaesthesia: A review. Indian J Anaesth 2002;46:87-95.

16. Olivot JM, Mlynash M, Kleinman JT, Straka M, Venkatasubramanian C, Bammer R, et al. MRI profile of the perihematomal region in acute intracerebral hemorrhage. Stroke 2010;41:2681-3.

17. Thiex R, Tsirka SE. Brain edema after intracerebral hemorrhage: Mechanisms, treatment options, management strategies, and operative indications. Neurosurg Focus 2007;22:E6.

18. Miller JD, Piper IR, Statham PF. ICP monitoring: Indications and techniques. . In: Narayan RK, Wreberger JE, Poulishock JT, editors. Neurotrauma. New York: McGraw Hill; 2002. p. 429-44.

19. Ayata C, Ropper AH. Ischaemic brain oedema. J Clin Neurosci 2002;9:113-24.

20. Posner JB, Plum F. The Diagnosis of Stupor and Coma. $3^{\text {rd }}$ ed. England: Oxford University Press; 1983. p. 4-830.

21. Ignatavicius DD, Workman ML. Medical-Surgical Nursing: Critical Thinking for Collaborative Care. St. Louis: Saunders; 2006. p. 1-3.

22. Goh J, Gupta AK. The management of head injury and intracranial pressure. Curr Anaesth Crit Care 2002;13:129-37.

23. Lejeune M, Howard T. Caring for patients with increased intracranial pressure: Find out what causes pressure to rise and how to intervene before complications occur. Nursing 2002;32:32cc31-5.

24. Hudak CM, Gallo BM, Morton PG. Critical Care Nursing: A Holistic Approach. $7^{\text {th }}$ ed. Philadelphia, PA: Lippincott Williams and Wilkins; 1998. p. $1-7$. 